\title{
Prevalence of blindness and low vision of people over 30 years in the Wenchi district, Ghana, in relation to eye care programmes
}

\author{
A C Moll, A J H van der Linden, M Hogeweg, W E Schader, J Hermans, R J W de Keizer
}

\begin{abstract}
A population based survey on the prevalence of major blinding disorders was conducted in the Wenchi district in central Ghana between March and May 1991. In 10 villages, 1425 people of 30 years and older were screened, using the WHO eye examination record. The prevalence of bilateral blindness above 30 years proved to be $1 \cdot 7 \%$ (best acuity $<3 / 60$ ): the prevalence of low vision above 30 years was $2.0 \%$ (best visual acuity $6 / 18$ to $3 / 60$ ). The causes of blindness were determined as cataract $(62 \cdot 5 \%)$, onchocerciasis $(12 \cdot 5 \%)$, corneal opacity (non-trachomatous) (8.2\%), refraction anomalies $(4 \cdot 2 \%)$, phthisis bulbi (4.2\%), optic atrophy (4.2\%), and vascular retinopathy $(4 \cdot 2 \%)$. In the Wenchi district, $1.0 \%$ of the population over the age of 30 years was found to need a cataract extraction because of blindness of both eyes. Another potential $1.0 \%$ needs a cataract extraction because of low vision. A minor second study $(n=149)$ was undertaken in the same district, but in a village in an area near the Black Volta river in which onchocerciasis is endemic. The prevalence of blindness $(8 \cdot 1 \%)$ and low vision (3.4\%) caused by onchocerciasis and cataract both proved to be higher. The survey provided the basis for a preventive and curative eye care programme.
\end{abstract}

(Br F Ophthalmol 1994; 78: 275-279)

Africa has a high rate of blindness which was estimated overall at $1 \cdot 2 \%$ in $1990 .^{1}$ In the most recent survey available for Ghana, on the west coast of Africa, in $1970,{ }^{2}$ the prevalence of blindness for the whole country was estimated at $0.7 \%$. This study was based on hospital data. In 1959 Rodger $^{3}$ had estimated a prevalence of blindness of $5 \%$ in northern Ghana. These percentages were also based on data from hospital records. However, when no information is available on the distribution of different causes of blindness in the general population, it is difficult to plan effective, preventive, and curative eye care programmes. Therefore Foundation 'Horizon Holland' in the Netherlands, in cooperation with the Leiden Department of Ophthalmology, initiated a population based survey of the prevalence and the causes of blindness and low vision in Ghana. The survey took place in the Wenchi district, which is part of the Brong-Ahafo region, a predominantly savannah area in central Ghana (Fig 1). Most of the, approximately, 123000 inhabitants live in a rural setting. A minor second survey was subsequently conducted in a village near the
Black Volta river, in an area in which onchocerciasis is endemic.

The aim of the study was to obtain baseline data as the first step in the development over the next few years of a preventive and curative eye care programme in the Wenchi district.

\section{Material and methods}

The field work for this study was conducted between March and May 1991. The sampling framework was chosen on the basis of data from the 1989 census figures for Ghana.

\section{WENCHI DISTRICT}

Health care in the Wenchi district comprises 15 $B$ level health clinics or health posts. We selected at random five of these clinics to cover the whole district. Within the areas of these clinics we randomly selected 10 villages with more than 1000 inhabitants, and in these villages a number of households was also randomly selected. Wenchi town was excluded because a better preventive eye care could be expected there (C level health facility); however, there is no eye care in the rest of Wenchi district.

The 10 villages were chosen outside the hyperendemic onchocerciasis area near the Black Volta river. The villages chosen for the main survey (Asuafo, Tainso, Adamu, Subinso, Nchiraa, Brahnam, Banda Ahenkro, Debibi, Tromeso, and Droboso) provide a sample group of 1425 inhabitants (all aged 30 years and older), which was about $1 \%$ of the total population of the district and included about $3 \%$ of the population older than 30 years. Only those older than 30 years (33\% of the population) were examined further because in the younger people a low incidence of blindness can be expected.

\section{BONGASE VILLAGE}

Separately, in another village (Bongase) in the Wenchi district but in an area near the Black Volta river in which onchocerciasis is endemic, a minor study was done on a sample group of 149 inhabitants.

\section{DATA COLLECTION}

The investigation team consisted of two examiners - that is, Dutch graduate medical students who had been trained in basic eye examination, and a Ghanaian interpreter/eye auxiliary. The team was locally supervised and supported by the district medical officer of health of the Wenchi district. 


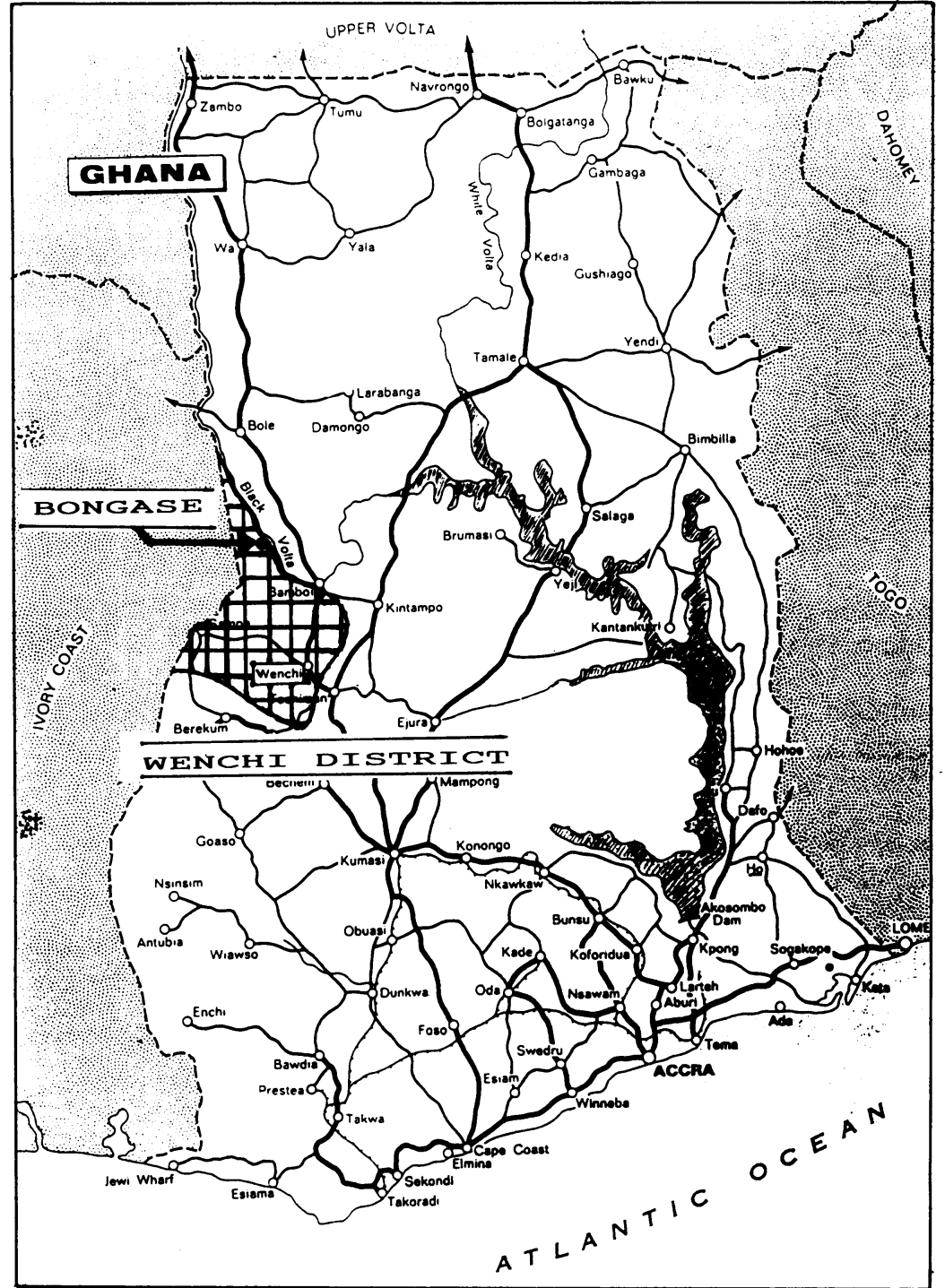

Figure 1 Map of Ghana showing Wenchi district.

Data were collected by means of the World Health Organisation (WHO) Eye Examination Record version $\mathrm{III}^{4}$ developed for the Prevention of Blindness Programme (PBL) by the WHO. The data per person were coded and recorded systematically.

\section{EYE EXAMINATION}

Firstly, the eye auxiliary tested the visual acuity in sunlight using the Snellen E chart. Vision was tested without correction and in case of a visual acuity of less than $6 / 18$, a pinhole visual acuity test was performed. Then, a basic eye examination was performed with a focal handlight, a loupe, and an ophthalmoscope in a (dark) room at the compound. Also the pupillary light reflex was tested. The examiner determined the main cause of visual loss in all eyes with a visual acuity less than 6/18. According to the WHO/PBL eye examination record the principal disorder, responsible for visual loss, was also noted after considering the disorders in the eyes most susceptible to treatment or prevention.

DEFINITIONS

The diagnosis 'cataract' was defined as a clinic- ally important central lens opacity that was visible with a loupe and a focal handlight. Opacity was graded with the rapid cataract grading method of Mehra and Minassian. ${ }^{5}$ This method is based on measurement of the area of the lens opacity that obscures the red reflex relative to the area of clear red reflex, as visualised through the undilated normal pupil.

Bilateral blindness was defined as an acuity of less than $3 / 60$ in the better eye and unilateral blindness as a visual acuity of less than $3 / 60$ in one eye.

Bilateral low vision was defined as a visual acuity of less than $6 / 18$, but better than or equal to $3 / 60$ in the better eye. Unilateral low vision was defined as a visual acuity of less than $6 / 18$ but better than or equal to $3 / 60$ in one eye.

\section{Results}

THE WENCHI SURVEY

In the Wenchi survey, visual acuity was measured in 962 of the 1425 individuals selected. Because the remaining 463 persons were not at home, their families were questioned about the vision of the absentees. The team was told that the absent persons were neither blind nor had severe eye problems. Therefore, these 463 persons were presumed to be not blind, in accordance with the WHO eye examination record.

The overall prevalence of bilateral blindness over the age of 30 years was $24 / 1425(1 \cdot 7 \%$, confidence limits (CL) $1 \cdot 1-2 \cdot 5 \%$ ) and the prevalence of bilateral low vision over the age of 30 years was $29 / 1425(2 \cdot 0 \%, C L 1 \cdot 4-2 \cdot 9 \%)$. The overall prevalences of unilateral blindness and unilateral low vision over the age of 30 years were $35 / 1425(2 \cdot 5 \%, \mathrm{CL} 1 \cdot 7-3 \cdot 4 \%)$ and $30 / 1425$ $(2 \cdot 1 \%$, CL $1 \cdot 4-3 \cdot 0 \%)$ respectively. In all categories the prevalence increased with age (Table 1).

The causes of blindness and low vision are shown in Table 2. Cataract was the major cause of bilateral blindness $(15 / 24)$, bilateral low vision $(15 / 29)$, unilateral blindness (19/35), and also of unilateral low vision (18/30). Onchocerciasis was the second most common cause of bilateral blindness (3/24) and accounted for unilateral blindness in two of the 35 cases. Non-trachomatous corneal opacity was responsible for bilateral blindness in two of the 24 cases, for bilateral low vision in three of the 29 , and for unilateral blindness in nine of the 35 cases found. Refraction error was the cause of bilateral blindness in one individual who lost his aphakic spectacle. It was the cause of bilateral low vision

Table 1 Age distribution of visual loss (Wenchi survey)

\begin{tabular}{lcccc}
\hline $\begin{array}{l}\text { Age } \\
\text { group } \\
\text { (years) }\end{array}$ & $\begin{array}{l}\text { No } \\
\text { persons }\end{array}$ & $\begin{array}{l}\text { Bilateral } \\
\text { blindness } \\
\text { No }(\%)\end{array}$ & $\begin{array}{l}\text { Bilateral } \\
\text { low vision } \\
\text { No }(\%)\end{array}$ & $\begin{array}{l}\text { Unilateral } \\
\text { blindness } \\
\text { No }(\%)\end{array}$ \\
\hline $30-39$ & 559 & $3(0 \cdot 5)$ & $1(0 \cdot 2)$ & $6(1 \cdot 1)$ \\
$40-49$ & 339 & $2(0 \cdot 6)$ & $2(0 \cdot 6)$ & $3(0 \cdot 9)$ \\
$50-59$ & 219 & $2(0 \cdot 9)$ & $6(2 \cdot 7)$ & $7(3 \cdot 1)$ \\
$60-69$ & 157 & $2(1 \cdot 3)$ & $7(1 \cdot 3)$ & $9(5 \cdot 7)$ \\
$70-79$ & 86 & $7(8 \cdot 1)$ & $5(5 \cdot 8)$ & $6(6 \cdot 9)$ \\
$80+$ & 65 & $8(12 \cdot 3)$ & $8(12 \cdot 3)$ & $4(6 \cdot 1)$ \\
All ages & 1425 & 24 & 29 & 35 \\
\hline
\end{tabular}


Table 2 Causes of visual loss in the group over age 30 in the rural population of the Wenchi district, Ghana

\begin{tabular}{lcll}
\hline & $\begin{array}{l}\text { Bilateral } \\
\text { blindness } \\
\text { No }(\%)\end{array}$ & $\begin{array}{l}\text { Bilateral } \\
\text { low vision } \\
\text { No(\%) }\end{array}$ & $\begin{array}{l}\text { Unilateral } \\
\text { blindness } \\
\text { No(\%) }\end{array}$ \\
\hline Cataract & $15(62 \cdot 5)$ & $15(51 \cdot 7)$ & $19(54 \cdot 3)$ \\
Onchocerciasis & $3(12 \cdot 5)$ & 0 & $2(5 \cdot 7)$ \\
Corneal opacity & $2(8 \cdot 2)$ & $3(10 \cdot 3)$ & $9(25 \cdot 7)$ \\
Refraction & $1(4 \cdot 2)^{\star}$ & $7(24 \cdot 2)$ & 0 \\
Glaucoma & 0 & 0 & $2(5 \cdot 7)$ \\
Phthysis & $1(4 \cdot 2)$ & 0 & 0 \\
Optic atrophy & $1(4 \cdot 2)$ & $2(6 \cdot 9)$ & 0 \\
Vascular retinopathy & $1(4 \cdot 2)$ & $2(6 \cdot 9)$ & $2(5 \cdot 7)$ \\
Chorioretinitis & 0 & 0 & $1(2 \cdot 9)$ \\
Total & 24 & 29 & 35 \\
\hline
\end{tabular}

^Person who lost aphakic spectacle.

in seven out of 29 cases and the cause of unilateral low vision in five out of 30 . Glaucoma was infrequently found; only two of the 35 people with unilateral blindness suffered from it. The number of glaucoma patients was probably higher, but we did not measure intraocular pressure.

THE BONGASE SURVEY

In the minor survey, 149 persons were selected in Bongase, a village in an area in which onchocerciasis is endemic. Out of these 149 randomly selected people, 115 were at home and had their visual acuity measured. Bilateral blindness above 30 years was found in 12 persons, the causes were cataract (five), onchocerciasis (six), and retinal disorder (one). Low vision above 30 years was found in five; the causes were cataract (two), onchocerciasis (two), and optic atrophy (one).

\section{Discussion}

In 1959 , Rodger ${ }^{3}$ estimated a $5 \%$ blindness in northern Ghana and listed the main causes as: onchocerciasis, trachoma, and senile cataract. In 1970 , Chatterjee ${ }^{2}$ estimated an overall blindness of $0.7 \%$ for the Ghanaian population as a whole, but for the southern part of the country the rate was $0.4 \%$. He noted, as major causes, cataract (39.0\%), glaucoma $(19 \cdot 8 \%)$, onchocerciasis $(11.9 \%)$, corneal opacities from measles and other origins $(10.8 \%)$; in $18.5 \%$, the cause of blindness could not be determined. Another survey conducted in west Africa (in the Gambia) showed a low prevalence of blindness $(0 \cdot 7 \%),{ }^{6}$ which can be explained by the absence of onchocerciasis. In a report on Togo (bordering

Table 3 Prevalence of blindness in population based surveys in Africa

\begin{tabular}{lllll}
\hline $\begin{array}{l}\text { Author } \\
\text { (ref no) }\end{array}$ & Year & Country & $\begin{array}{l}\text { No of persons } \\
\text { examined }\end{array}$ & $\begin{array}{l}\text { Prevalence } \\
(\%)\end{array}$ \\
\hline Whitfield (9) & 1981 & Kenya & 13803 & $0 \cdot 7$ \\
WHO(8) & 1983 & Malawi & 1574 & $1 \cdot 3 \star$ \\
WHO (8) & 1985 & Chad & 5002 & $1 \cdot 5-3 \cdot 1$ \\
Bucher (13) & 1985 & Transvaal & 18962 & $0 \cdot 57$ \\
Balo(7) & 1986 & Togo & 11081 & $0 \cdot 6-1 \cdot 1$ \\
Faal (6) & 1986 & The Gambia & 8174 & $0 \cdot 7$ \\
Rapoza (11) & 1986 & Tanzania & 1827 & $1 \cdot 26$ \\
Negrel (12) & 1988 & The Congo & 6185 & $0 \cdot 3$ \\
Loewental (10) & 1989 & Kenya & 900 & $1 \cdot 1$ \\
Whitworth(14) & & Sierra Leone & 1625 & $1 \cdot 3$ \\
Moll & 1991 & Ghana & 1425 & $1 \cdot 7 \dagger$ \\
\hline
\end{tabular}

*Above 6 years, fabove 30 years, łcurrent paper.
Ghana), ${ }^{7}$ bilateral blindness was $0 \cdot 82 \%$ for the country as a whole. Other similar surveys on blindness in Africa and other regional surveys are summarised in Table $3 .^{8-14}$

The prevalence of blindness described here for the Wenchi district is relatively high $(1 \cdot 7 \%)$ in comparison with the figures found in other population based studies $(0 \cdot 3$ to $3 \cdot 1 \%$; mean $1 \cdot 0 \%$, median $0 \cdot 8 \%$ ). This could be due to the higher age of the persons in our sample group. The people over 30 years comprise one third of the population, the estimated prevalence of bilateral blindness for all ages will be $0 \cdot 54$. This number is more in line with the Gambia. The prevalence of low vision was $2 \cdot 0 \%$. This could be a minimum estimate of low vision since some of the absentees could have been partially sighted; in this case a history alone could be not sufficient.

The $67 \cdot 5 \%$ overall coverage in our study was lower than that for the study in the Gambia $(94 \%){ }^{6}$ However, our data were collected in March and April, just before the onset of the rainy season. The difference can be explained by the amount of farmwork in this (planting) season, when the inhabitants of the villages leave home early in the morning and return late in the afternoon. In agreement with the WHO instructions, it is possible to take the history of the vision of absentees by questioning the family members at home. If eye problems were reported, we made sure we examined the absentees later.

\section{CAUSES OF BLINDNESS AND LOW VISION}

\section{Cataract}

In Africa ${ }^{15}$ and in Asia ${ }^{16}$ cataract is reported to be the main cause of blindness. This was also the case in our study; cataract was the major cause of blindness $(15 / 24,62 \cdot 5 \%)$ and low vision $(15 / 29$, $51.7 \%)$. Of our population, $1.0 \%$ needed cataract surgery because of blindness and another $1 \%$ potentially need surgery because of low vision. In Wenchi town, as in the Wenchi district, there is no curative eye care at all. Ghana, like many African countries, has only one ophthalmologist per one million inhabitants. ${ }^{15}$ In Africa as a whole it is estimated that three million people are waiting for an operation $^{17}$ and it is clear that solving the problems of blindness caused by cataract requires more ophthalmologists and trained ophthalmic medical assistants. ${ }^{18}$ In 1989 , the first group of 17 students entered a 12 month course in Accra (Ghana) for the ophthalmic nursing diploma. ${ }^{19}$ They are trained for diagnosis and management of common ophthalmic disorders. A new 18 month diploma of ophthalmology for medical doctors has begun, to meet the need for cataract surgeons. Experienced expatriate ophthalmologists can contribute greatly to the selection of operable patients and they can help to develop and to perform cataract surgery with appropriate technology. ${ }^{17} 19$

\section{Onchocerciasis}

Active onchocerciasis was responsible for three of the 24 cases of blindness $(12.5 \%)$ in the Wenchi district. In Bongase, in which onchocerciasis is endemic, the prevalence of 
onchocerciasis was far higher. Unfortunately, the sample group $(n=149)$ was too small to allow estimation of percentage of the causes of the blindness and low vision.

Onchocerciasis is a typical west African problem, ${ }^{1420-25}$ except for the Gambia. In Togo, for instance, the prevalence ranges from $3.9 \%$ to $28.5 \%$, depending on the region. ${ }^{7}$

Since 1975 an ambitious long term control programme has been operational in the most seriously affected areas of west Africa. This Onchocerciasis Control Programme (OCP) aims at stopping the transmission of onchocerciasis by eliminating the black fly vectors. This has been done by spraying by helicopter the breeding sites of the black fly with a selective larvicide. In addition, in 1982 ivermectin was introduced for the treatment of human onchocerciasis. Since this is not a macrofilaricidal drug, treatment must be repeated once or preferably twice a year for 15 to 20 years. ${ }^{24}$

In the Wenchi district, once a year an onchocerciasis team visits all the villages within 1 $\mathrm{km}$ of the Black Volta river to treat onchocerciasis patients with ivermectin. The village in our survey that was nearest to the Black Volta river (Banda Ahenkro) showed the highest prevalence of blindness caused by onchocerciasis, but ivermectin was not available there. We encountered the same problem in Bongase where onchocerciasis was endemic: in nearly every house somebody had signs of onchocerciasis. But since Bongase is $4 \mathrm{~km}$ away from the Black Volta river, the OCP teams did not visit it (personal information from the medical assistant). In our opinion, all patients in areas with endemic onchocerciasis should receive ivermectin to prevent blindness. We realise that this presents a real logistic problem in rural areas.

\section{Corneal opacity}

Corneal opacities were responsible for two out of 24 cases of blindness and three out of 29 cases of low vision. The group with bilateral blindness was too small for data on the cause of blindness; most likely causes were familial corneal disorders, ophthalmia neonatorum, and use of traditional eye medicines. Trachoma and xerophthalmia were rare in the Wenchi district: we saw only one person, a young woman, with trichiasis.

According to a report by Sarkies, ${ }^{25}$ trachoma is presumably a bigger problem in the north of Ghana; in 1952 he indicated that the main causes of blindness in northern Ghana were onchocerciasis and trachoma. ${ }^{25}$ The north of Ghana is poorer, drier, and dustier than the Wenchi district (subtropical/savannah) and less water is available. Water is essential for simple measures of hygiene: for instance facial cleansing prevents the transmission of trachoma. ${ }^{26}$

Xerophthalmia was also not seen in the Wenchi district during a study in 1990 by Van der Does and Knook (personal communication). A prerequisite for xerophthalmia is malnutrition and, in particular, vitamin A deficiency.$^{27}$ In the Wenchi district (pro)vitamin A is available that is, dark green leafy vegetables, papayas, mangoes, and red palm oil.
Corneal opacity caused unilateral blindness in nine of the 35 cases. It is likely that farm accidents were responsible for the majority of the uniocular scars.

\section{Glaucoma}

Glaucoma, responsible for two out of 35 cases of unilateral blindness, was undoubtedly underestimated, as the basic eye examination we used assessed the visual acuity and funduscopy without systemic measurement of the eye pressure and the visual field. Exact data on population based prevalence are not available for glaucoma. There is, however, some information from Ghanaian hospitals. As far as we know, in the ophthalmic department in Agogo $10 \%$ of the unilaterally blind patients and $27 \%$ of the bilaterally blind patients had glaucoma. ${ }^{28}$ Another study on glaucoma, performed in northern Ghana, showed that 206 of the 397 patients with chronic glaucoma (52\%) were already blind on admission. ${ }^{29}$ In 1991, in Ghana, a national programme on the prevention of blindness started in Accra: diagnosis and treatment of glaucoma for 1 week free of charge.

\section{Refractive error}

A high rate of bilateral low vision (seven out of 29) and unilateral low vision (five out of 30 ) in the Wenchi population was due to uncorrected refractive errors. This cause of visual loss can easily be tackled by provision of appropriate optical services. However, spectacles are too expensive for the ordinary person. Furthermore, spectacles are only available in the big cities, which are too far away for most people. Travelling is also expensive for these people. In the planning of vision services a low cost workshop should supply these needs.

\section{Conclusion}

In the Wenchi district in central Ghana $1 \%$ of the population over the age of 30 is blind from treatable cataract. There is a lack of ophthalmically trained personnel to deal with this problem. Doctors, nurses, and other paramedical workers need training in eye care. As a first step in establishing preventive and curative eye care in the Wenchi district, a Dutch team will go there not only to perform cataract extractions, but also to teach the basics of eye care and cataract surgery to a selected group of interested local medical personnel.

In spite of the intense programme, the prevalence of onchocerciasis is still high near the Black Volta river. More ivermectin distribution programmes are urgently needed to cover all the villages on both sides of the river over a much wider area than the $1 \mathrm{~km}$ zone treated so far.

The authors thank all who assisted in this project, in particular Mr Yeboah-Antwi, at the time district medical officer of health, Wenchi district, Mrs M Hagan, ophthalmologist in Accra, Mr J M C de Bekker project coordinator Wenchi, 'Horizon Holland', and Mrs H Bijlmer-Gorter, ophthalmologist, the Netherlands.

1 Foster A, Johnson GJ. Magnitude and causes of blindness in the developing world. Int Ophthalmol 1990; 14: 135-40. 
2 Chatterjee S. Blindness in Ghana and its rehabilitation. Ghana Med f 1970: 314-5.

3 Rodger FC. Blindness in West Africa. London: HK Lewis, 1959

4 World Health Organisation Programme for the Prevention of blindness. Eye examination record, version III. Unpublished mimeographed document. Geneva: WHO, 1988: WHO/PBL/88.1.

5 Mehra V, Minassian DC. A rapid method of grading cataract in epidemiological studies and eye surveys. Brf Ophthalmol 1988; 72: 801-3.

6 Faal H, Minassian D, Sowa S, Foster A. National survey of blindness and low vision in the Gambia: results. Br f Ophthalmol 1989; 73: 82-7.

7 Balo K, Negrel DA. Les causes de cecite au Togo. F Fr Ophtalmol 1989; 12: 291-5.

8 World Health Organisation. Available Data on Blindness (Updata 1987). World Health Organisation, Geneva. Unpublished Document WHO/PBL/87.14.

9 Whitfield R, Schwab L. Ross-Degnan D, Steinkuller P, Swartwood J. Blindness and eye disease in Kenya: ocular status survey results from the Kenya Rural Blindness Prevention Project. Br f Ophthalmol 1990; 74: 333-40.

10 Loewenthal R, Pe'er J. A prevalence survey of ophthalmic diseases among the Turkana tribe in North-West Kenya. Br F Ophthalmol 1990; 74: 84-8.

11 Rapoza PA, West SK, Katala SJ, Taylor HR. Prevalence and causes of vision loss in central Tanzania. Int Ophthalmol $1991 ; 15: 123-9$.

12 Negrel AD, Masembo-Yako B, Botoka E, Minassian DC, Coddy-Zitsamele R. Prevalence et causes de la cecite en Republique populaire du Congo. Int Ophthalmol 1991; 14: 140 .

13 Bucher PJM, Ijsselmuiden CB. Prevalence and causes of blindness in the Northern Transvaal. Brf Ophthalmol 1988; 72: 721-6.
14 Whitworth JAG, Gilbert CE, Mabey DM, Morgan D, Foster A. Visual loss in an onchocerciasis endemic community in Sierra Leone. Brf Ophthalmol 1993; 77: 30-2.

15 Foster A. Cataract blindness in Africa. Ophthalmic Surg 1987; 18: $384-8$

16 Chatterjee A, Milton RC, Thyle S. Prevalence and aetiology of cataract in the Punjab. Brf Ophthalmol 1982; 66: 35-42.

17 Foster A. Who will operate on Africa's 3 million curable blind people? Lancet 1991; 337: 1267-9.

18 Johnson GJ, Foster A. Training in community ophthalmology. Int Ophthalmol 1990; 14: 221-6.

19 Schwab L. Cost-effective cataract surgery in developing nations. Ophthalmic Surg 1987; 18: 307-9.

JAG, Gilbert CE Maybe DM, Maude GH, Morgan D, Taylor DW. Effects of repeated doses of ivermectin on ocular onchocerciasis: community-based trial in Sierra Leone. Lancet 1991; 338: 1100-3.

21 Stilma JS, Bridger S. Causes and prevalence of blindness in the Northern Province of Sierra Leone. Doc Ophthalmol 1983; 56: $115-22$

22 Newland HS, White AT, Greene BM, Murphy RP, Taylor H. Ocular manifestations of onchocerciasis in a rain forest area of West Africa. Brf Ophthalmol 1991; 75: 163-9.

23 Taylor HR Onchocerciasis. Int Ophthalmol 1990; 14: 189-94.

24 Van der Lelij A. Immunological and therapeutical aspects of ocular onchocerciasis. Thesis Free University Amsterdam, ocular onchocerciasis. Thesis Free University Amsterdam, 25 Sarkies JWR. Ocular onchocerciasis. Br f Ophthalmol 1952; 36: 81-99.

26 Taylor HR. Trachoma. Int Ophthalmol 1990; 14: 201-4.

27 Sommer A. Xerophthalmia, keratomalacia and nutritional blindness. Int Ophthalmol 1990; 14: 195-9.

28 Cofie G, Tenkorang J, Thomson I. Blindness in Ghana - a hospital-based survey. Comm Eye Health 1991; 7: 9-10.

29 Verrey JD, Foster A, Wormald R, Akuamoa C. Chronic glaucoma in Northern Ghana - a retrospective study of 397 patients. Eye 1990; 4: 115-20. 